ISSN 0103-5150

Fisioter. Mov., Curitiba, v. 29, n. 1, p. 193-208, Jan./Mar. 2016

Licenciado sob uma Licença Creative Commons

DOI: http://dx.doi.org.10.1590/0103-5150.029.001.AR04

\title{
Assessment of the strength of the lower limb muscles in subjects with stroke with portable dynamometry: a literature review
}

\author{
Avaliação da força muscular de membros inferiores pós-ave \\ pela dinamometria portátil: uma revisão da literatura
}

Júlia Caetano Martins, Larissa Tavares Aguiar, Eliza Maria Lara, Juliana Braga Moura, Lucas Araújo Castro e Souza, Luci Fuscaldi Teixeira-Salmela, Christina Danielli Coelho de Morais Faria*

Universidade Federal de Minas Gerais, (UFMG), Belo Horizonte, MG, Brazil

\begin{abstract}
Introduction: Weakness of the lower limb muscles, which are the main impairments after stroke, is associated with reduced mobility and decreased performance in functional tasks. Therefore, the assessment of strength of these muscles is necessary, which is commonly assessed with portable dynamometry. Aims: To perform a literature review regarding the methods used to assess lower limb strength with portable dynamometry in subjects with stroke and to describe its investigated measurement properties with this population. Materials and Methods: An extensive search was performed on the MEDLINE, SCIELO, LILACS, and PEDro databases, by combining specific key words, followed by active manual search by two independent researchers. Results and Discussion: Thirty studies were included, and the muscular groups of the knee (90\%) were the most assessed, followed by the ankle (66.7\%) and hip (63.3\%) joints. In 5\% of the studies,
\end{abstract}

* JCM: MSc, e-mail: julia_caetano@yahoo.com.br LTA: MSc, e-mail: larissatavaresaguiar@gmail.com EML: MSc, e-mail: izamlara@yahoo.com.br JBM: grad, e-mail: bmoura.juliana@gmail.com LACS: MSc, e-mail: lucasouza16@yahoo.com.br LFTS: PhD, e-mail: lfts@ufmg.br

CDCM: PhD, e-mail: cdcmf@ufmg.br 
there were not reported any descriptions related to the positioning of the subjects and the equipment, neither regarding the stabilization procedures. Only $50 \%$ provided information regarding the number of trials and only $46.7 \%$ regarding the contraction times, being three trials and 5 s the most commonly applied. Only $10 \%$ provided feedback and $23.3 \%$ demonstrations, prior to data collection. Only seven studies $(23.3 \%)$ investigated the measurement properties of portable dynamometry and reported moderate to high reliability levels. Final Considerations: The protocols used for the assessment of the strength of the lower limb muscles with portable dynamometry in subjects with stroke were not standardized. Moreover, only one measurement property was investigated: the reliability, which was considered adequate.

Keywords: Stroke. Dynamometer. Lower limbs. Muscular strength. Assessment.

\section{Resumo}

Introdução: A fraqueza muscular de membros inferiores (MMII) é uma das principais deficiências do Acidente Vascular Encefálico (AVE), associada à redução da mobilidade e da execução de tarefas funcionais. Portanto, é necessária a avaliação da força muscular desses segmentos, o que é comumente realizado com a dinamometria portátil. Objetivos: Verificar os protocolos utilizados para a avaliação da força muscular de MMII com o dinamômetro portátil em indivíduos pós-AVE e as propriedades de medida investigadas. Métodos: Foram realizadas buscas nas bases de dados MEDLINE/SCIELO/LILACS/PEDro com combinação de termos específicos, seguida de busca manual ativa. Dois examinadores independentes analisaram os estudos e extraíram as informações. Resultados: Foram incluídos 30 estudos, sendo os grupos musculares do joelho os mais comumente avaliados (90\%), seguido do tornozelo (66,7\%) e quadril (63,3\%). Em 5\% dos estudos, não houve qualquer descrição do posicionamento dos indivíduos, do equipamento e nem da estabilização adotada. Apenas 50\% relatou o número de repetições e apenas $46,7 \%$ o tempo da contração muscular, sendo três repetições e cinco segundos de contração os mais utilizados. Poucos relataram uso de feedback imediato e verbal (10\%) e demonstração (23,3\%) antes da coleta dos dados. Apenas sete estudos (23,3\%) investigaram as propriedades de medida do dinamômetro portátil, sendo investigada a confiabilidade com resultados significativos, de moderada a elevada magnitude. Considerações finais: Não houve uma padronização clara dos protocolos utilizados na avaliação da força muscular de MMII com o dinamômetro portátil em indivíduos pós-AVE e apenas uma propriedade de medida foi investigada: a confiabilidade, com resultados adequados.

Palavras-chave: Acidente Vascular Cerebral. Dinamômetro de Força Muscular. Força Muscular. Extremidade Inferior. Avaliação.

\section{Introduction}

Stroke is defined as a brain injury produced by changes in the blood supply, which causes a set of neurological symptoms, which last for at least 24 hours (1). The neurological deficits caused by the stroke may lead to disabilities, which can last for months or remain for years, resulting in high burden to the patients, their families and to the health systems (2). Amongst the impairments caused by the stroke, muscular weakness is the most commonly observed (3).

Weakness of the lower limb (LL) muscles may lead to limitations in the ability to perform functional tasks, such as gait $(4,5)$, stair ascent and descent $(6)$, and sit-tostand transfers (7) and increases in energy expenditure to perform these tasks (6). Strength impairments of the LL muscles in subjects with stroke can increase the risk of falls 2.9 times, when compared with healthy subjects (8). Muscular strengthening programs $(7,9,10)$ may modify these strength deficits, that affect gait speed (5) and functional mobility $(7,9,10)$. Therefore, muscular strength must be carefully assessed, to guide clinical decision-making in stroke rehabilitation.

Nowadays, the method mostly used for the assessment of strength within clinical settings is the Manual Muscular Test (MMT). However, the MMT has some limitations: it is inaccurate $(11,12)$, subjective, when muscular strength is rated as good or normal $(12,13,14)$, and shows low responsiveness $(12,15)$. Therefore, to accurately assess strength, it is necessary to apply a valid 
(16), reliable $(11,15)$, and sensitive (11) method, that provides objective measures $(11,17)$, such as portable dynamometry. Portable dynamometers are commonly used in research (18) and, in some situations, within clinical settings. They are easy-to-use devices and to perform the tests, the device is positioned between the examiner's hand and the muscular group under assessment, similar to the MMT assessment $(12,18)$. Some factors may influence the measures obtained with portable dynamometers (19), such as positioning of the subjects and the device, number of trials, contraction and resting times, prior demonstration and familiarization with the procedures, and supply of verbal or visual encouragements. Some factors do not directly influence the acquisition of the strength measures, nevertheless, they could be important for the analyses of the results, such as unilateral or bilateral assessments, and the measurement properties of portable dynamometry for the assessment of strength in subjects with stroke $(11,15)$.

In this context, the aims of the present study were: to perform a review of the literature, to verify if there were standardized protocols for the assessment of the strength of the LL muscles in subjects with stroke with portable dynamometry, as well as to verify which measurement properties were already investigated using this device with this population. Standardized protocols, employed for the assessment of muscular strength with portable dynamometry, would facilitate the test reproducibility within clinical and research contexts, which are important for comparisons between studies and evaluations.

\section{Methods}

Searches were performed on the MEDLINE (via PubMed), SCIELO, LILACS, and PEDro databases. The MEDLINE search strategy followed the recommendations of the Cochrane group (20), which was modified to suit the other databases. To select the studies related to the purpose of this review, the following descriptors related to LL and portable dynamometry, were used: "lower limb", "lower extremity", "membrum inferius", feet, foot, ankle, knee, hip, shank, leg, and thigh, dynamometer and "hand-held dynamometer". To be included, the studies should report in their method sections the evaluation of the strength of the lower limb muscles with portable dynamometers in subjects with stroke and be published until August, 2015. There were no restrictions regarding language of data of publication.
Two independent examiners selected the studies, following three steps. The first step consisted of screening the titles of all studies found in the databases and excluding those that clearly did not meet the previously established criteria, followed by critical analyses of the abstracts, and the full papers. From the references of the selected studies, an active manual search was also performed, which followed the same criteria and procedures above described. Furthermore, when there was a disagreement between the examiners, a third reviewer resolved by consensus.

\section{Results}

The electronic search identified 808 studies. In the first step, 672 were excluded, for not meeting the inclusion criteria. In the second step, 63 studies were excluded and in the third step, eight studies were excluded. The 65 studies that met the inclusion criteria, 42 were duplicates. Thus, 23 studies were included from the electronic search. From the active manual search of these 23 studies, nine others were included. However, two could not be retrieved. Therefore, a total of 30 studies were included in this systematic review (Figure 1). The main reasons for the exclusion of the studies were the use of isokinetic dynamometers and/or assessment of strength in healthy subjects or in subjects with other diseases.

All of the 30 studies reported at least one clinical and demographic information of the included sample. In total, 965 subjects of both sexes, with ages ranging between 17 and 88 years, were evaluated. Moreover, the time since the onset of the stroke was also reported by the majority of the studies, ranging from acute (three days) to chronic (4934 days) phases, as shown in Table 1.

Of the 30 studies included in this review, 19 (63.3\%) assessed the strength of the hip joint muscles, being the flexor muscles the most evaluated $(6,11,15,20$, 21, 23 - 28, 32, 33, 40, 41, 43, 44, 46) (Table 2). The strength of the knee joint muscles was assessed in 27 $(90 \%)$ studies and the extensor muscles were the most assessed (6, 11, 15, 21-30, 32, 33, 35 - 46) (Table 2). Twenty studies (66.7\%) assessed the strength of the ankle joint muscles and the dorsiflexors were the most described (11, 15, 22 - 25, 27-33, 37, 38, 40, 44, 46, 47) (Table 2). Only two studies $(6.7 \%)(33,34)$ assessed the strength of the soleus muscle. Twenty-four (80\%) studies performed bilateral measures of strength $(6$, $22,23,25,28$ - 33, 34 - 37, 40 - 47). 




Figure 1 - Flow chart of the selection of the studies

Table 1 - Clinical and demographic characteristics of the participants included in the 30 studies that assessed the strength of the lower limb muscles with portable dynamometry in subjects with stroke

(To be continued)

\begin{tabular}{|c|c|c|c|c|}
\hline Study & Age & Sex & Sample size & Time since stroke \\
\hline Bohannon (15) & 17 to $82($ mean $=51.9)$ years & $\mathrm{NI}$ & $N=16$ & $\mathrm{NI}$ \\
\hline Bohannon (21) & $60.8 \pm 8.4$ years & $\mathrm{F}(7) ; \mathrm{M}(13)$ & $N=20$ & 24 to $187(68.0 \pm 46.6)$ days \\
\hline Bohannon et al. (11) & $\mathrm{NI}$ & $\mathrm{NI}$ & $N=21$ & $\mathrm{NI}$ \\
\hline Bohannon (22) & 33 to $86(61.9 \pm 12.1)$ years & $\mathrm{F}(21) ; \mathrm{M}(16)$ & $N=37$ & 7 to $437(66.5 \pm 81.7)$ days \\
\hline Riddle et al. (23) & 23 to $85(54.6 \pm 18.1)$ years & $\mathrm{NI}$ & $\mathrm{N}=37$ & 150 to $4.500($ mean $=1560)$ days \\
\hline Bohannon et al. (24) & 34 to $87(67 \pm 14)$ years & $\mathrm{F}(5) ; \mathrm{M}(15)$ & $N=20$ & 3 to 347 days \\
\hline Bohannon (25) & 22 to $88($ mean $=63.3)$ years & $\mathrm{F}(14) ; \mathrm{M}(16)$ & $N=30$ & $\mathrm{NI}$ \\
\hline Stein et al. (26) & 24 to $54(33 \pm 10)$ years & $\mathrm{NI}$ & $N=09$ & $\mathrm{NI}$ \\
\hline Cameron et al. (27) & 29 to $77(53.7 \pm 3.1)$ years & $F(4) ; M(11)$ & $N=15$ & Subacute phase \\
\hline Andrews et al. (28) & 44 to $85(63.8 \pm 11.6)$ years & $\mathrm{F}(17) ; \mathrm{M}(31)$ & $N=48$ & $19.9 \pm 9.7$ days \\
\hline Bohannon (29) & $\mathrm{NI}$ & $\mathrm{Nl}$ & $N=39$ & $\mathrm{NI}$ \\
\hline Andrews et al. (30) & 35 to $82(61.6 \pm 12.7)$ years & $F(24) ; M(26)$ & $N=50$ & 3 to 60 days \\
\hline Lin et al. (31) & 31 to $82(61.7 \pm 13.9)$ years & $F(16) ; M(52)$ & $N=68$ & $1.427 \pm 2.142$ days \\
\hline Akbari et al. (32) & 40 to $60(49.05 \pm 6.2)$ years & $\mathrm{F}(15) ; \mathrm{M}(19)$ & $N=34$ & $1.035 \pm 791$ days \\
\hline Moriello et al. (33) & Mean $=67$ years & $F(20) ; M(43)$ & $N=63$ & 90 to $365($ mean $=120)$ days \\
\hline Guimarães et al. (34) & 30 to 65 years & $\mathrm{NI}$ & $N=15$ & $\mathrm{NI}$ \\
\hline
\end{tabular}


Table 1 - Clinical and demographic characteristics of the participants included in the 30 studies that assessed the strength of the lower limb muscles with portable dynamometry in subjects with stroke

(Conclusion)

\begin{tabular}{lcccc}
\hline Study & Age & Sex & Sample size & Time since stroke \\
\hline Bale et al. (35) & $\mathrm{Nl}$ & $\mathrm{NI}$ & $\mathrm{N}=18$ & $\mathrm{NI}$ \\
\hline Liu et al. (6) & 15 to 85 years & $\mathrm{F}(15) ; \mathrm{M}(15)$ & $\mathrm{N}=30$ & 25 to 357 days \\
\hline Faria et al. (36) & 26 to $80(54.7 \pm 5.4)$ years & $\mathrm{F}(10) ; \mathrm{M}(12)$ & $\mathrm{N}=22$ & $1.566 \pm 1.476,6$ days \\
\hline Mong et al. (37) & $60.0 \pm 4.8$ years & $\mathrm{F}(6) ; \mathrm{M}(6)$ & $\mathrm{N}=12$ & $\geq 365$ days \\
\hline Ng (38) & 50 to $70(59.8 \pm 5.1)$ years & $\mathrm{F}(30) ; \mathrm{M}(48)$ & $\mathrm{N}=78$ & $1.533 \pm 1.387$ days \\
\hline Kiyama et al. (39) & $(63.9 \pm 7.2$ years) & $\mathrm{F}(6) ; \mathrm{M}(14)$ & $\mathrm{N}=20$ & $730 \pm 1.241$ days \\
\hline Cooper et al. (40) & 44 a $88(66.0 \pm 11.1)$ years & $\mathrm{F}(7) ; \mathrm{M}(13)$ & $\mathrm{N}=20$ & 30 to 1.410 days \\
\hline Wong et al. (41) & $57.26-7.19$ & $\mathrm{~F}(8) ; \mathrm{M}(27)$ & $\mathrm{N}=35$ & At least 360 days \\
\hline Michaelsen et al. (42) & $\mathrm{Nl}$ & $\mathrm{F}(2) ; \mathrm{M}(8)$ & $\mathrm{N}=10$ & $1.890 \pm 1.200$ days \\
\hline Ng et al. (43) & $57.3 \pm 7.2$ & $\mathrm{~F}(8) ; \mathrm{M}(27)$ & $\mathrm{N}=35$ & 174 (84.6) days \\
\hline Souza et al. (44) & 30 to $86(57.80 \pm 13.8)$ years & $\mathrm{F}(30) ; \mathrm{M}(29)$ & $\mathrm{N}=59$ & 210 to 11.100 (2.729 \pm 2.140$)$ days \\
\hline Prasomsri et al. (45) & $59.1 \pm 9.5$ & $\mathrm{~F}(11) ; \mathrm{M}(34)$ & $\mathrm{N}=45$ & $172.5 \pm 186.9$ days \\
\hline Kim et al. (46) & $59.2 \pm 7.7$ & $\mathrm{~F}(15) ; \mathrm{M}(15)$ & $\mathrm{N}=30$ & $4.934 \pm 159.9$ days \\
\hline Ng et al. (47) & $62.0 \pm 6.2$ & $\mathrm{~F}(11) ; \mathrm{M}(26)$ & $\mathrm{N}=37$ & $234 \pm 90$ days \\
\hline
\end{tabular}

Note: $\mathrm{NI}=$ not informed; $\mathrm{F}$ : Female; M: Male; N: number of subjects with stroke.

Table 2 - Data extraction of the 30 studies, which assessed the strength of the lower limb muscles with portable dynamometry in subjects with stroke and provided information regarding the positioning or the data collection protocol

(To be continued)

\begin{tabular}{|c|c|c|c|}
\hline Study & Muscular Groups & Positioning & Protocol \\
\hline Bohannon (15) & $\begin{array}{c}\text { Hip Flex/Ext and Abd/Add; ; } \\
\text { Knee Flex/Ext } \\
\text { Ankle DF/PF }\end{array}$ & $\begin{array}{l}\text { Hip Flex/Ext: SP, hip flexed at } 90^{\circ} \text { and knees relaxed. } \\
\text { Hip Abd/Add: SP, hip in neutral in the frontal plane and knees } \\
\text { extended. Knee Flex/Ext: Sitting, legs pending. } \\
\text { Ankle DF/PF: SP, hip and knees extended. } \\
\text { Equipment positioning: } \\
\text { Hip Flex/Ext: on the distal third and anterior/posterior part of } \\
\text { the thigh, trunk stabilization with strap. } \\
\text { Hip Abd/Add: on the distal third and lateral/medial part of } \\
\text { the thigh, trunk stabilization contralateral/ipsilateral to the LL } \\
\text { tested. } \\
\text { Knee Flex/Ext: on the distal third and posterior/anterior part of } \\
\text { the thigh, segment stabilization with strap. } \\
\text { Ankle DF/PF: on the head of the metatarsal bones over the } \\
\text { anterior/posterior part of the foot, ankle stabilization with } \\
\text { strap. }\end{array}$ & $\begin{array}{l}3 \text { trials, } \\
\text { Contraction time: } 4-5 \mathrm{~s}\end{array}$ \\
\hline
\end{tabular}


Table 2 - Data extraction of the 30 studies, which assessed the strength of the lower limb muscles with portable dynamometry in subjects with stroke and provided information regarding the positioning or the data collection protocol

(To be continued)

\begin{tabular}{|c|c|c|c|}
\hline Study & Muscular Groups & Positioning & Protocol \\
\hline Bohannon (21) & $\begin{array}{l}\text { Hip Flex/Ext/Abd; } \\
\text { Knee Flex/Ext; } \\
\text { Ankle DF/PF }\end{array}$ & $\begin{array}{l}\text { Hip Flex: SP, hip flexed at } 90^{\circ} \text { and knees relaxed. } \\
\text { Hip Ext: SP, hip and knees flexed at } 90^{\circ} \text {. } \\
\text { Hip Abd: SP, hips in neutral of abduction and knees extended. } \\
\text { Knee Flex/Ext: Sitting with hips and knees flexed at } 90^{\circ} \text {. } \\
\text { Ankle DF/PF: SP. } \\
\text { Equipment positioning: } \\
\text { Hip Flex/Ext: on the distal third and anterior/posterior part of } \\
\text { the thigh, trunk stabilization with strap. } \\
\text { Hip Abd: on the distal third and lateral part of the thigh, trunk } \\
\text { stabilization contralateral to the LL to be tested. } \\
\text { Knee Flex/Ext: on the distal third and posterior/anterior part of } \\
\text { the thigh, segment stabilization with strap. } \\
\text { Ankle DF/PF: on the head of the metatarsal bones over the } \\
\text { anterior/posterior part of the foot, leg stabilization with strap. }\end{array}$ & Contraction time: $4 \mathrm{~s}$ \\
\hline $\begin{array}{l}\text { Bohannon et al. } \\
\text { (11) }\end{array}$ & $\begin{array}{l}\text { Paretic Hip Flex; Knee Ext; } \\
\text { Ankle DF }\end{array}$ & $\begin{array}{l}\text { Hip Flex; Ankle DF: SP. } \\
\text { Knee Ext: Seated position. }\end{array}$ & $\begin{array}{c}4 \text { trials, } \\
\text { Contraction time: } 5 \mathrm{~s}\end{array}$ \\
\hline Bohannon (22) & $\begin{array}{l}\text { Bilateral Knee Ext; Ankle DF/ } \\
\text { PF }\end{array}$ & $\mathrm{NI}$ & $\mathrm{NI}$ \\
\hline $\begin{array}{l}\text { Riddle et al. } \\
\text { (23) }\end{array}$ & $\begin{array}{c}\text { Bilateral Hip Flex; Knee Flex/ } \\
\text { Ext; Ankle DF }\end{array}$ & $\begin{array}{l}\text { Hip Flex; Ankle DF: SP. } \\
\text { Knee Flex/Ext: Seated with legs pending. }\end{array}$ & $\begin{array}{l}3 \text { trials, } \\
\text { Contraction time: } 4-6 \mathrm{~s} \\
\text { Rest interval: } 10-30 \mathrm{~s}\end{array}$ \\
\hline Bohannon (25) & $\begin{array}{c}\text { Bilateral Hip Flex/Abd; Knee } \\
\text { Ext; Ankle DF }\end{array}$ & $\begin{array}{l}\text { Hip Flex and Abd; Ankle DF: SP. } \\
\text { Knee Ext:Seated. }\end{array}$ & $\begin{array}{l}2 \text { trials, } \\
\text { Contraction time: } 4-6 s\end{array}$ \\
\hline Stein et al. (26) & Hip Flex; Knee Flex/Ext & $\begin{array}{l}\text { Hip Flex; Knee Flex/Ext: Seated with legs pending. } \\
\text { Equipment positioning: } \\
\text { Knee Flex/Ext: on the distal third and posterior/anterior part of } \\
\text { the thigh. }\end{array}$ & Contraction time: $15 \mathrm{~s}$ \\
\hline $\begin{array}{l}\text { Cameron et al. } \\
\text { (27) }\end{array}$ & $\begin{array}{l}\text { Paretic Hip Flex; Knee Ext; } \\
\text { Ankle DF }\end{array}$ & $\begin{array}{l}\text { Equipment positioning: } \\
\text { Hip Flex: on the distal third and anterior part of the thigh. }\end{array}$ & $\mathrm{NI}$ \\
\hline $\begin{array}{l}\text { Andrews et al. } \\
\text { (28) }\end{array}$ & $\begin{array}{c}\text { Bilateral Hip Flex; Knee Flex/ } \\
\text { Ext; Ankle DF }\end{array}$ & $\begin{array}{l}\text { Hip Flex; Ankle DF: SP. } \\
\text { Knee Flex/Ext: Seated. } \\
\text { Equipment positioning: } \\
\text { Knee Flex/Ext: on the distal third and posterior/anterior part of } \\
\text { the thigh. }\end{array}$ & Contraction time: $5 \mathrm{~s}$ \\
\hline Bohannon (29) & Bilateral Knee Ext & $\begin{array}{l}\text { Seated, knee flexed at } 90^{\circ} \text {, and legs perpendicular to the floor. } \\
\text { Equipment positioning: on the distal third and anterior part of } \\
\text { the thigh. }\end{array}$ & Contraction time: 3 - $5 \mathrm{~s}$ \\
\hline $\begin{array}{l}\text { Andrews et al. } \\
\text { (30) }\end{array}$ & $\begin{array}{l}\text { Bilateral Hip Flex; Knee Ext; } \\
\text { Ankle DF }\end{array}$ & $\begin{array}{l}\text { Hip Flex; Knee Ext; Ankle DF: Seated. } \\
\text { Equipment positioning: } \\
\text { Hip Flex: on the distal third and anterior part of the thigh. } \\
\text { Knee Flex/Ext: on the distal third and posterior/anterior part of } \\
\text { the thigh. } \\
\text { Ankle DF: on the head of the metatarsal bones, dorsal part of } \\
\text { the foot. }\end{array}$ & $\mathrm{NI}$ \\
\hline Lin et al. (31) & Bilateral Ankle DF/PF & $\begin{array}{l}\text { Ankle DF: SP, hip and knees extended. } \\
\text { Ankle PF: SP, hips and knees flexed at } 90^{\circ} \text { (LL supported on } \\
\text { a block). }\end{array}$ & $\begin{array}{l}5 \text { trials, } \\
\text { Contraction time: } 5 \mathrm{~s} \\
\text { Rest interval: } 60 \mathrm{~s}\end{array}$ \\
\hline
\end{tabular}


Table 2 - Data extraction of the 30 studies, which assessed the strength of the lower limb muscles with portable dynamometry in subjects with stroke and provided information regarding the positioning or the data collection protocol

(To be continued)

\begin{tabular}{|c|c|c|c|}
\hline Study & Muscular Groups & Positioning & Protocol \\
\hline & & $\begin{array}{l}\text { Equipment positioning: } \\
\text { Ankle DF/PF: on the head of the metatarsal bones over the } \\
\text { anterior/posterior part of the foot, stabilization with strap. }\end{array}$ & \\
\hline $\begin{array}{l}\text { Akbari et al. } \\
\text { (32) }\end{array}$ & $\begin{array}{l}\text { Bilateral Hip Flex/Ext/Abd; } \\
\text { Knee Flex/Ext; Ankle DF/PF }\end{array}$ & $\begin{array}{l}\text { Hip Flex; Knee Flex/Ext; Ankle DF: Seated with hips, knees and } \\
\text { ankles flexed at } 90^{\circ} \text {. } \\
\text { Hip Ext: LP. } \\
\text { Ankle PF: PP, knees and ankles flexed at } 90^{\circ} \text {. } \\
\text { Equipment positioning: } \\
\text { Hip Flex/Ext: on the distal third and anterior/posterior part of } \\
\text { the thigh. } \\
\text { Hip Abd: on the distal third and lateral part of the thigh, trunk } \\
\text { stabilization contralateral to the tested LL tested. } \\
\text { Knee Flex/Ext: on the distal third and posterior/anterior part of } \\
\text { the thigh. } \\
\text { Ankle DF/PF: on the head of the metatarsal bones, over the } \\
\text { anterior/posterior part of the foot. }\end{array}$ & $\mathrm{NI}$ \\
\hline $\begin{array}{l}\text { Moriello et al. } \\
\text { (33) }\end{array}$ & $\begin{array}{l}\text { Bilateral Hip Flex/Ext; Knee } \\
\text { Flex/Ext; Ankle DF/PF }\end{array}$ & $\begin{array}{l}\text { Hip Flex: Seated, legs pending; SP, hips and knees flexed; LP, } \\
\text { hips extended and knees flexed. } \\
\text { Hip Ext: Standing over a table, hips and knees extended; PP, } \\
\text { hips and knees extended; LP, hips and knees flexed. } \\
\text { Knee Flex: PP, knees flexed < } 90^{\circ} \text {; LP, knees extended. } \\
\text { Knee Ext: Seated, legs pending; LP, knees flexed. } \\
\text { Ankle DF: Seated, feet supported on the floor; LP, knees flexed and } \\
\text { ankles in plantar flexion. } \\
\text { Ankle PF: PP, knees extended; PP, knee flexed at } 90^{\circ} \text { and feet } \\
\text { pending; LP, knee flexed at } 90^{\circ} ; \text { LP, knees extended. } \\
\text { Equipment positioning: } \\
\text { Hip Flex/Ext: on the distal third and anterior/posterior part of } \\
\text { the thigh. } \\
\text { Knee Flex/Ext: on thee distal third and posterior/anterior part } \\
\text { of the leg. } \\
\text { Ankle DF/PF: on the head of the metatarsal bones, over the } \\
\text { anterior/posterior part of the foot. }\end{array}$ & 3 trials \\
\hline $\begin{array}{l}\text { Guimarães et al. } \\
(34)\end{array}$ & Bilateral soleus muscles & $\mathrm{NI}$ & $\mathrm{NI}$ \\
\hline Bale et al. (35) & Bilateral Knee Flex/Ext & Seated, hips flexed at $90^{\circ}$. & 3 trials \\
\hline Liu et al. (6) & Bilateral Hip Flex; Knee Ext & Hip Flex; Knee Ext: Seated with back supported. & $\mathrm{NI}$ \\
\hline Faria et al. (36) & Bilateral Knee Ext & $\mathrm{NI}$ & 3 trials \\
\hline Mong et al. (37) & $\begin{array}{l}\text { Bilateral Hip Flex; Knee Flex/ } \\
\text { Ext; Ankle DF/PF }\end{array}$ & $\begin{array}{l}\text { Hip Flex; Knee Flex/Ext: Seated on a high chair, hips and knees } \\
\text { flexed at } 90^{\circ} \text {. } \\
\text { Ankle DF/PF: Seated, knees extended. } \\
\text { Equipment positioning: } \\
\text { Hip Flex: on the distal third and anterior part of the thigh, trunk } \\
\text { stabilization with strap. } \\
\text { Knee Flex: on the distal third and posterior part of the leg, segment } \\
\text { stabilization with strap. } \\
\text { Knee Ext: on the distal third and anterior part of the leg, waist } \\
\text { stabilization with strap. } \\
\text { Ankle DF/PF: on the head of the metatarsal bones over the } \\
\text { anterior/posterior part of the foot, waist stabilization with } \\
\text { strap. }\end{array}$ & $\begin{array}{c}3 \text { trials, } \\
\text { Rest interval: } 1-2 \mathrm{~min}\end{array}$ \\
\hline
\end{tabular}


Table 2 - Data extraction of the 30 studies, which assessed the strength of the lower limb muscles with portable dynamometry in subjects with stroke and provided information regarding the positioning or the data collection protocol

(To be continued)

\begin{tabular}{|c|c|c|c|}
\hline Study & Muscular Groups & Positioning & Protocol \\
\hline $\mathrm{Ng}(38)$ & $\begin{array}{c}\text { Bilateral Knee Flex/Ext; Ankle } \\
\text { DF/PF }\end{array}$ & $\mathrm{NI}$ & $\mathrm{NI}$ \\
\hline $\begin{array}{l}\text { Kiyama et al. } \\
\text { (39) }\end{array}$ & Bilateral Knee Ext & $\begin{array}{l}\text { Seated. } \\
\text { Equipment positioning: on the distal third and anterior part of } \\
\text { the thigh, stabilization of the pelvis with strap. }\end{array}$ & $\begin{array}{c}3 \text { trials, } \\
\text { Contraction time: } 5 \mathrm{~s} \\
\text { Rest interval: } 30 \mathrm{~s}\end{array}$ \\
\hline $\begin{array}{l}\text { Cooper et al. } \\
(40)\end{array}$ & $\begin{array}{l}\text { Bilateral Hip Flex/Ext/Abd; } \\
\text { Knee Flex/Ext; Ankle DF/PF }\end{array}$ & $\begin{array}{l}\text { Hip Flex/Ext: SP, hips flexed at } 90^{\circ} \text { and kneed relaxed. } \\
\text { Knee Flex/Ext: Seated. } \\
\text { Ankle DF/PF: SP, hips and knees extended. } \\
\text { Equipment positioning: } \\
\text { Hip Flex/Ext: on the distal third and anterior/posterior part of } \\
\text { the thigh, trunk stabilization with strap. } \\
\text { Hip Abd: on the distal third and lateral part of the thigh, trunk } \\
\text { stabilization contralateral to the tested LL. } \\
\text { Knee Flex/Ext: on the distal third and posterior/anterior part of } \\
\text { the thigh, segment stabilization with strap. } \\
\text { Ankle DF/PF: on the head of the metatarsal bones over the } \\
\text { anterior/posterior part of the foot. }\end{array}$ & $\begin{array}{c}1 \text { trial, } \\
\text { Contraction time: } 5 \mathrm{~s}\end{array}$ \\
\hline Wong et al. (41) & Bilateral Hip Abd; Knee Ext & $\begin{array}{l}\text { Hip Abd: SP. } \\
\text { Knee Ext: Seated, hips and knees flexed at } 90^{\circ} \text {. } \\
\text { Equipment positioning: } \\
\text { Hip Abd: on the lateral part of the thigh, } 5 \mathrm{~cm} \text { proximal to the } \\
\text { lateral femoral epicondyle. } \\
\text { Knee Ext: on the anterior part of the leg, } 5 \mathrm{~cm} \text { proximal to the } \\
\text { medial malleolus. }\end{array}$ & $\mathrm{NI}$ \\
\hline $\begin{array}{l}\text { Michaelsen et } \\
\text { al. (42) }\end{array}$ & Bilateral Knee Flex & $\begin{array}{l}\text { SP, hips and knees flexed at } 90^{\circ} \text {, legs supported and feet } \\
\text { pending; PP, hips in neutral and knees flexed at } 90^{\circ} \text {. } \\
\text { Equipment positioning: } \\
\text { Knee Ext: on the distal part of the leg, proximal to the lateral } \\
\text { malleolus. }\end{array}$ & $\begin{array}{c}3 \text { trials, } \\
\text { Contraction time: } 4 \mathrm{~s} \\
\text { Rest interval: } 2 \text { min }\end{array}$ \\
\hline Ng et al. (43) & Bilateral Hip Abd; Knee Ext & $\begin{array}{l}\text { Hip Abd: SP. } \\
\text { Knee Ext: Seated, hips and knees flexed at } 90^{\circ} \text {. } \\
\text { Equipment positioning: } \\
\text { Hip Abd: on the lateral part of the thigh, } 5 \mathrm{~cm} \text { proximal to the } \\
\text { lateral femoral epicondyle. } \\
\text { Knee Ext: on the anterior part of the leg, } 5 \mathrm{~cm} \text { proximal to the } \\
\text { medial malleolus. }\end{array}$ & $\begin{array}{c}3 \text { trials, } \\
\text { Rest interval: } 2 \text { min }\end{array}$ \\
\hline Souza et al. (44) & $\begin{array}{l}\text { Bilateral Hip Flex/Ext/Abd; } \\
\text { Knee Flex/Ext; Ankle DF/PF }\end{array}$ & $\begin{array}{l}\text { Hip Flex/Ext: SP, hips and knees flexed at } 90^{\circ} \text {. } \\
\text { Hip Abd: SP, hips in neutral and knees extended. } \\
\text { Knee Flex/Ext: Seated, hips and knees flexed at } 90^{\circ} \text {. } \\
\text { Ankle DF/PF: SP, hips and knees extended. } \\
\text { Equipment positioning: } \\
\text { Hip Flex/Ext: on the anterior/posterior part of the thigh, } \\
\text { proximal to the knee. } \\
\text { Hip Abd: on the lateral part of the thigh, proximal to the knee. } \\
\text { Knee Flex/Ext: on the posterior/anterior part of the leg, } \\
\text { proximal to the ankle, stabilization on the distal and anterior } \\
\text { part of the thigh. } \\
\text { Ankle DF/PF: on the anterior/posterior part of the foot, } \\
\text { proximal to the metatarsophalangeal joints, stabilization on the } \\
\text { distal and anterior part of the leg. }\end{array}$ & $\begin{array}{l}3 \text { trials, } \\
\text { Contraction time: } 5 \mathrm{~s}, \\
\text { Rest interval: } 15 \mathrm{~s}\end{array}$ \\
\hline
\end{tabular}


Table 2 - Data extraction of the 30 studies, which assessed the strength of the lower limb muscles with portable dynamometry in subjects with stroke and provided information regarding the positioning or the data collection protocol

(Conclusion)

\begin{tabular}{|c|c|c|c|}
\hline Study & Muscular Groups & Positioning & Protocol \\
\hline $\begin{array}{l}\text { Prasomsri et al. } \\
\text { (45) }\end{array}$ & Bilateral Knee Ext; Ankle PF & $\mathrm{NI}$ & $\mathrm{NI}$ \\
\hline Kim et al. (46) & $\begin{array}{c}\text { Bilateral Hip Flex/Ext; Knee } \\
\text { Flex/Ext; Ankle DF/PF }\end{array}$ & $\begin{array}{l}\text { Hip Ext; Knee Flex; Ankle PF: PP. } \\
\text { Hip Flex; Knee Ext: Seated. } \\
\text { Ankle DF: SP. }\end{array}$ & $\mathrm{NI}$ \\
\hline Ng et al. (47) & Bilateral Ankle DF/PF & $\begin{array}{l}\text { Ankle DF/PF: SP. } \\
\text { Equipment positioning: } \\
\text { On the anterior/posterior part of the foot, over the middle third } \\
\text { of the metatarsals }\end{array}$ & $\begin{array}{c}3 \text { trials, } \\
\text { Contraction time: } 3 \mathrm{~s}, \\
\text { Rest interval: } 1 \mathrm{~min}\end{array}$ \\
\hline
\end{tabular}

Note: $\mathrm{NI}=$ note informed; Flex=flexors; Ext=extensors; $\mathrm{Abd}=$ abductors; $\mathrm{Add}=$ aductors; $\mathrm{DF}=$ dorsiflexors; $\mathrm{PF}=$ plantar flexors; $\mathrm{LL}=$ lower limb; $\mathrm{SP}=$ supine position; $\mathrm{PP}=$ prone position; $\mathrm{LP}=$ lateral position

Of the 30 included studies, five (16.7\%) $(22,27,34$, $38,45)$ did not provide information regarding the procedures of stabilization and positioning of the subjects and the dynamometer. Table 2 shows the positioning and stabilization procedures adopted in the included studies.

Of the studies that assessed the strength of the hip flexor muscles, 16 (53.3\%) $(6,15,21,23,24$ $26,28,30,32,33,37,39,40,44,46)$ described the positioning of the subjects and the supine position, with the hips and knees in extension, was adopted in six (20\%) studies $(23-25,28,30,39)$. All the eight studies, which assessed the strength of the hip extensor muscles, reported the positioning of the subjects and half $(50 \%)(15,21,40,44)$, adopted the supine position with the hips and knees flexed. The seven studies $(15,21,22,32,41,43,44)$ that assessed the strength of the hip abductor muscles, all adopted the supine position. The only study that assessed the strength of hip adductor muscles (15) adopted the supine position with the hip in neutral in the frontal plane and knees extended.

Of the 15 studies that assessed the strength of the knee flexor muscles, 14 (93.3\%) (15, 21, 23, 24, 26, 28, $32,33,35,37,40,42,44,46)$ described the subjects' positioning and $11(73.3 \%)(15,21,23,24,26,28$, $32,35,37,40,44$ ) adopted the sitting position with the legs pending and knees flexed at $90^{\circ}$. Considering the $26(86.7 \%)$ studies that assessed the strength of the knee extensor muscles, 21 (80.77\%) $(6,11,15$, 21 - 30, 32, 33, 35 - 41, 43 - 46) reported the subjects' positioning and all adopted the sitting position. Only one study (33) assessed the strength of the knee extensor muscles with the subjects lying on their side.

Of the 19 studies, that assessed the strength of the ankle dorsiflexor muscles, $14(73.7 \%)(15,21,11,23$ $25,28,31,32,33,37,40,44,47)$ described the subjects' positioning, and $12(63.2 \%)(15,21,11,23-25,28$, $31,32,40,44,47$ ) adopted the supine position, but the angles of the ankle joints were not specified. Of the 14 studies $(15,21,22,31,32-34,37,38,40,44$ - 47) that assessed the strength of the ankle plantar flexor muscles, 10 (71.4\%) (15, 21, 31, -32 - 33, 37, 40, 44 47) described the subjects' positioning, and six (60\%) $(15,21,31,40,44,47)$ adopted the supine position, with varied positions of the hip and knee joints.

Of all the included studies, 15 (50\%) (11, 15, 23, $25,31,33,35-37,39,40,42-44,47$ ) reported the number of trials used to obtain the strength measures and $11(73.3 \%)(15,23,33,35-37,39,42-44$, 47) performed three trials. Regarding the duration of the maximal isometric contractions, $14(11,15$, $21,23,25,26,28,29,31,39,40,42,44,47)$ studies provided this information and six $(42.9 \%)(11,15$, $28,31,40,44)$ reported five seconds of contractions. Only eight studies $(26.7 \%)(23,31,37,39,42,43,44$, 47 ) reported the resting time intervals between the trials, which was quite variable (Table 2 ).

Few studies reported the use of visual or verbal feedback, to motivate the participants during the performance of maximal isometric contractions. Only 
three studies $(10 \%)(11,39,44)$ reported the use of immediate verbal feedback. The demonstration and familiarization procedures were also rarely reported. Six studies (20\%) reported that the demonstration procedures were carried out and used verbal instructions $(15,28,31,37,40,44)$ and two studies used movement instructions $(15,44)$. Six studies $(20 \%)$ $(15,30,35,37,39,44)$ reported the familiarization procedures with the participants performing the same test procedures, prior to data collection.

Of the 30 included studies, which investigated the measurement properties of portable dynamometry for the assessment of strength in subjects with stroke, only seven $(23.3 \%)(11,15,23,27,33,35)$ reported some data and reliability was the only measurement property investigated. Three studies $(10 \%)(23,33$, 46) assessed intra-rater reliability; one (14.3\%) (11) inter-rater reliability, two $(28.6 \%)(15.35)$ test-retest reliability, and one (14.28\%) (27) internal consistency. All of these studies reported significant values with correlation coefficients above 0.70 , indicating moderate to high reliability levels, based upon the classification adopted by Portney and Watkins (48) (Table 3). All muscular groups of the LL assessed with portable dynamometry had some type of reliability investigated.

Table 3 - Results of the seven studies which assessed the measurement properties of portable dynamometry

\begin{tabular}{|c|c|c|c|c|}
\hline Study & Sample & Muscular Groups & $\begin{array}{l}\text { Measurement } \\
\text { Properties* }\end{array}$ & Results \\
\hline Bohannon (15) & $\mathrm{N}=21 ; 17-82$ years & $\begin{array}{c}\text { Hip Flex/Ext/Abd/Add; Knee Flex/ } \\
\text { Ext; Ankle DF/PF }\end{array}$ & $\begin{array}{l}\text { Test-retest } \\
\text { reliability }\end{array}$ & $\begin{array}{c}0.84 \leq r \leq 0.99 \\
p<0.01\end{array}$ \\
\hline Bohannon et al. (11) & $N=21$ & Hip Flex; Knee Ext; Ankle DF & Inter-rater reliability & $\begin{aligned} 0.84 & \leq r \leq 0.91 \\
p & <0.001\end{aligned}$ \\
\hline Riddle et al. (23) & $\begin{array}{l}\mathrm{N}=37 ; 23-85 \text { years; time } \\
\text { since stroke: } 150 \text { - 4,500 days }\end{array}$ & Hip Flex; Knee Flex/Ext; Ankle DF & $\begin{array}{l}\text { Intra-rater } \\
\text { reliability }\end{array}$ & $\begin{array}{c}0.88 \leq \mathrm{ICC} \leq 0.97 ; p \\
<0.05\end{array}$ \\
\hline Cameron et al. (27) & $\begin{array}{l}\mathrm{N}=15 ; \mathrm{F}(4), \mathrm{M}(11) ; 29-77 \\
\text { years; time since stroke: } \\
\text { subacute phase }\end{array}$ & Hip Flex; Knee Ext; Ankle DF & $\begin{array}{l}\text { Internal } \\
\text { consistency }\end{array}$ & $\begin{array}{c}\text { Cronbach's alpha }= \\
0.73 ; P<0.001\end{array}$ \\
\hline Moriello et al. (33) & $\begin{array}{c}\mathrm{N}=63 ; \mathrm{F}(20), \mathrm{M}(43) \text {; mean } \\
\text { age: } 67 \text { years; time since } \\
\text { stroke: } 90-365 \text { days }\end{array}$ & $\begin{array}{c}\text { Hip Flex/Ext; Knee Flex/Ext; Ankle } \\
\text { DF/PF }\end{array}$ & $\begin{array}{l}\text { Intra-rater } \\
\text { reliability }\end{array}$ & $\begin{array}{c}0.87 \leq r \leq 0.99 ; p< \\
0.01\end{array}$ \\
\hline Bale et al. (35) & $N=18$ & Knee Flex/Ext & $\begin{array}{l}\text { Test-retest } \\
\text { reliability }\end{array}$ & $\mathrm{ICC}>0.70 ; p \leq 0.05$ \\
\hline Kim et al. (46) & $\begin{array}{l}\mathrm{N}=30 ; \mathrm{F}(15) ; \mathrm{M}(15) ; 59.20 \\
\quad \pm 7.72 \text { years; time since } \\
\text { stroke } 4,934 \pm 159.9 \text { days }\end{array}$ & $\begin{array}{c}\text { Hip Flex/Ext; Knee Flex/Ext; Ankle } \\
\text { DF/PF }\end{array}$ & $\begin{array}{l}\text { Intra-rater } \\
\text { reliability }\end{array}$ & $0.72 \leq \mathrm{ICC} \leq 0.89$ \\
\hline
\end{tabular}

Note: ${ }^{*}$ Transcription of the nomenclature adopted by the authors; Flex=flexors; Ext=extensors; $A b d=$ abductors; $A d d=a d u c t o r s ; ~ D F=d o r s i-$ flexors; $P F=$ plantar flexors; $I C C=$ intra-class correlation coefficient; $r=$ Pearson correlation coefficient; $F=$ female; $M=$ male

\section{Discussion}

The aims of this study were to perform a review of the literature to verify if there were standardized protocols for the assessment of the strength of the LL muscles of subjects with stroke with portable dynamometry, as well as to verify which measurement properties were already investigated using this equipment with this population. There was found large sample variability, including adults and elderly, male and female, at the acute, subacute, and chronic phases of stroke. The muscular groups of the knee were the most commonly assessed (90\%), followed by ankle (66.7\%), and hip muscles (63.3\%). Over half of the studies provided information about the subjects' positioning employed for the assessment 
of strength of the LL muscles and the supine position was the most used. Five studies did not describe the positioning of the subjects and the dynamometer, neither the stabilization procedures during data collection. Of the $50 \%$ of the studies, which reported the number of trials of muscular contraction, $73.3 \%$ performed three trials. Only $46.7 \%$ reported duration of the maximal isometric contractions and $42.9 \%$ used five seconds. Few studies reported the use of immediate verbal feedback $(10 \%)$ and demonstration $(23.3 \%)$. Few studies (23.3\%) investigated the measurement properties of the portable dynamometer and reliability was the only property assessed, with significant results showing moderate to high reliability levels.

Strength measures were shown to be predictive of functional capacity and motor skills, length of hospital stay, and rehabilitation time (30). Muscular weakness of the LL muscles in subjects with stroke, for example, may be associated with reduced walking speed (21). In addition, strength deficit of the extensor muscles of the LL may be a limiting factor for the sit-to-stand performance and gait. The leg muscles play an important role to support impacts of high magnitude (34). The selection of the muscular groups assessed by the studies included in this review could be explained by the fact that these muscular groups can be more or less recruited for the task being performed (33), and these muscles are involved in many activities, such as walking, ascending and descending stairs, and making transfers $(30,33)$.

Although extensive search for studies that evaluated the strength of the LL muscles with portable dynamometry, only one study measured the strength of the hip adductor muscles in subjects with stroke and none assessed the strength of the external and internal hip rotator muscles. According to Kendall et al. (13), weakness of the hip adductor muscles can compromise the efficiency in performing hip flexion, since they also act as hip flexors. As a result, this could lead to decreases in mobility (10), walking speed (6), and the ability to ascend and descend stairs (5). Weakness of the external hip rotators may be associated with medial rotation of the femur, followed by foot pronation, which causes knee valgus (13). Moreover, weakness of the internal hip rotators may laterally rotate the femur during the standing position and gait (13). Muscular weakness of the hip rotators will negatively affect mobility of these subjects (13). Therefore, it is also necessary to assess the strength of these muscular groups in subjects with stroke, since the weakness of the LL muscles is often observed in this population and may be associated with limitations in performing some functional activities $(3,4,5,6)$.

Most of the studies (80\%) evaluated the strength of the LL muscles, bilaterally. Muscular weakness in subjects with stroke is observed in both paretic and non-paretic limbs (49). The primary reason for the weakness of the non-paretic limb is related to the neuroanatomical characteristics, since approximately $10 \%$ of the descending motor fibers do not cross to the contralateral side, also leading to changes in strength in the muscles of the ipsilateral side of the brain injury (50). In addition, muscular atrophy that results from prolonged inactivity, enhances the weakness (51). Hamrin et al. (52) found that, in general, the torque of the knee flexor and extensor muscles in subjects with stroke is lower in faster movements and during flexion than during extension, when compared with healthy subjects. To determine the most affected side, the differences in strength between the paretic and non-paretic sides for a specific muscular group, can be calculated. Lower the differences, better will be the strength symmetry between the limbs of subjects with stroke (35).

When comparing the positions used in the studies included in the present review with those most commonly described for the clinical assessment of strength in healthy subjects using the MMT $(13,53)$, some differences were observed. To measure the strength of the knee flexor and extensor muscles, the majority of the included studies adopted the seated position with the legs pending, and knee flexed at $90^{\circ}$. Kendall et al. (13), however, adopted the prone position with the thigh supported on a stretcher, hip with slight external rotation and knees flexed between $50^{\circ}$ and $70^{\circ}$ for the flexor muscles, and the seated position for the knee extensor muscles. In relation to the assessment of the hip flexors and extensors, and ankle dorsiflexors and plantar flexors, most studies adopted the supine position. For Kendall et al. (13), however, the positioning of the subjects was different, except for the hip flexor and ankle dorsiflexor muscles. According to them, the strength of the hip extensor and ankle plantar flexor muscles should be measured in prone position. Magee (53), however, evaluated the isometric strength of the LL muscles in the supine position, varying the hip and knee flexion angles, according to the muscular group to be tested. Only one study measured the strength of the 
hip and knee flexor/extensor muscles of subjects with stroke in the lateral position, reducing the action of the gravity on the tested segment (33). Further studies of this nature are needed to establish the best positioning of the individual and to facilitate the reproducibility of strength tests of the LL muscles within clinical and research contexts.

The stabilization of the segment to be tested, which varied with the adopted positioning, is also an important factor to assure that the subjects with stroke do not use compensatory strategies that may affect the results. Considering this, when assessing the strength of the hip flexor/extensor/abductor/ adductor muscles in the supine position, most studies provided stabilization of the trunk, while Kendall et al. (13) stabilized the pelvis contralateral for the hip flexors, in the supine position, and ipsilateral, for the hip extensors, in the prone position. For the knee flexor and extensor muscles, in the seated position, the distal third and anterior aspects of the thigh were stabilized in most studies. However, Kendall et al. (13) provided stabilization on the ipsilateral pelvis and posterior third and medial aspects of the thigh of the respective muscular groups in the prone position. Finally, for the ankle dorsiflexor and plantar flexor muscles, in the supine position, stabilization was provided at the ankle, whereas Kendall et al. (13) did not adopt any stabilization procedures. However, stabilization may be particularly difficult for the clinician, who is not always physically strong (15) and often requires the use of straps or belts, to ensure that the test is performed in the standard position, without interference of compensatory movements.

All studies, which reported the positioning of the device, positioned the dynamometer perpendicularly to the distal third of the assessed segment, so that the evaluator applied a force contrary to the direction of the movement. Although Kendall et al. (13) and Magee (53) performed sub-maximal strength tests of the LL muscles by means of isometric contractions, without using the hand-held dynamometer, both provided manual resistance on the distal third of the segment to be tested. This illustrates the positioning pattern of the applied resistance by the examiner.

Most of the studies included in the present review used three trials of muscular contractions, and the number of trials ranged from one to four. Recent studies that investigated if the number of trials (first trial, means of two and three trials) could affect the strength measurements with portable dynamometry with both subacute and chronic stroke subjects showed that only one trial, after familiarization, was sufficient to provide consistent results $(54,55$, 56). Therefore, although the majority of the previous studies used three trials for the assessment of strength with portable dynamometry in subjects with stroke, the use of fewer trials, specifically one after familiarization, can be applied, which enhance the applicability of the tests and decrease the evaluation time and the effect of muscle fatigue during strength tests in subjects with stroke $(54,55)$.

Considering the isometric contraction time with portable dynamometry in subjects with stroke, most studies adopted five seconds. However, other studies adopted contraction times ranging between three and six seconds, except for one study, which adopted 15 seconds. According to Brum et al. (57), isometric contractions can increase blood pressure, since there is a mechanical obstruction of blood flow in response to isometric contractions, followed by accumulation of metabolites that activate chemoreceptors of the autonomic nervous sympathetic system, associated with increases in the peripheral vascular resistance. Fernandes and Marins (58) showed that the best isometric contraction time for healthy individuals was three seconds, in order to avoid this effect. Considering that the majority of subjects with stroke also has hypertension, it is necessary to carefully control the contraction time.

Few studies provided information regarding the rest time between the measurements. Moreover, the rest interval between trials ranged from 10 seconds to two minutes. Although rest time has not been commonly reported, it is important to reduce fatigue during strength tests $(39,59)$. According to Nogueira et al. (59), adequate rest intervals can reverse the fatigue mechanism and provide time for energy recovery of the assessed muscular group. If this rest interval is insufficient, the muscular group can fatigue and this will negatively influence the values obtained with the measurements of strength. In the absence of a standardization procedure regarding the rest interval time to be used when evaluating individuals with stroke, it is always important to provide some rest intervals between the measurements of strength and to verify signs of muscle fatigue. Futures studies aiming at establishing the best rest intervals for this population during portable dynamometry strength tests may help the evaluation process. 
The demonstration and familiarization procedures were scarcely reported, although they are important to minimize the learning effects during data collection (39). Considering that individuals with stroke have difficulties in performing muscular contractions, particularly on their paretic side, in addition to difficulties in understanding the procedures, the provision of incentives are even more essential to obtain adequate measures of strength (49). However, only two studies included in the present literature review reported the use of incentives during the evaluation of strength.

Only seven studies $(23.33 \%)$ investigated the measurement properties of portable dynamometry for the assessment of strength of the of LL muscles with subjects with stroke. Reliability was the only measurement property investigated. The test-retest and intra-rater reliabilities were the most investigated, probably due to the fact that is easier to collect data related to repeated measurements obtained by the same examiner, which is commonly used within clinical settings (measures of the same professional are compared before and after an intervention). Although the best statistical method to investigate the reliability of measurements obtained at different sessions or different examiners is the calculation of Intraclass Correlation Coefficients, as they reflect both the associations and the agreement levels between two or more quantitative measures $(23,48)$, the majority of the studies reported the Pearson Correlation coefficients, which is not the most adequate method, since it only assesses the degree of association between the measures, regardless of the degree of agreement $(23,48)$.

None of the studies included in this review investigated the validity of portable dynamometry for the assessment of strength in subjects with stroke. Portable dynamometers are devices comprised of strength cells and, therefore, have adequate face validity for strength measurements. In addition, adequate concurrent-related validity was reported by a previous study that compared the measures provided by portable dynamometers with those provided by isokinetic dynamometers in subjects with various health conditions (16). Considering that the validity of an instrument depends upon the context and the population (48), it is necessary to verify the criterion-related validity of portable dynamometers for the assessment of strength of the LL muscles in subjects with stroke, so that they can be used for this purpose.

\section{Final Considerations}

The use of portable dynamometry in subjects with stroke was most commonly employed for the assessment of the strength of the knee joint muscles, followed by the ankle and hip joint muscles. The majority of the studies provided some information regarding the positioning of the subjects during the tests, being the supine position mostly used. Some studies reported the procedures of stabilization of the tested segment and the distal third was the predominant site. The data collection protocols, regarding the number of trials, contraction time, and resting intervals were described in some studies; however, they were not standardized. Few studies reported procedures related to demonstration, familiarization, and/or incentives, which motivate maximal muscular contractions. Few studies investigated the measurement properties of portable dynamometry and the only assessed property was reliability, but with questionable statistical methods. Portable dynamometry seems to provide reliable measures of strength of the LL muscles in subjects with stroke and although there were not found any standardized protocols, it is a useful method to be employed within clinical contexts, since it provides objective measures of muscular strength.

\section{References}

1. Sacco RL, Kasner SE, Broderick JP, Caplan LR, Connors JJ, Culebras A, Elkind MS, George MG, Hamdan AD, Higashida RT, Hoh BL, Janis LS, KaseCS,Kleindorfer DO, Lee JM, Moseley ME, Peterson ED, Turan TN, Valderrama AL, Vinters HV; American Heart Association Stroke Council, Council on Cardiovascular Surgery and Anesthesia; Council on Cardiovascular Radiology and Intervention; Council on Cardiovascular and Stroke Nursing; Council on Epidemiology and Prevention; Council on Peripheral Vascular Disease; Council on Nutrition, Physical Activity and Metabolism. An updated definition of stroke for the 21st century: a statement for healthcare professionals from the American Heart Association/American Stroke Association. Stroke. 2013 Jul;44(7):2064-89. 
2. Mozaffarian D, Benjamin EJ, Go A, Arnett DK, Blaha MJ, Cushman M, et al. Heart disease and stroke statistics-2015 update: a report from the American Heart Association. Circulation 2015;131(4):29-322.

3. Bohannon RW. Muscle strength and muscle training after stroke. J Rehabil Med. 2007 Jan;39(1):14-20.

4. Pradon D1, Roche N, Enette L, Zory R. Relationship between lower limb muscle strength and 6-minute walk test performance in stroke patients. J Rehabil Med. 2013 Jan;45(1):105-8.

5. Dorsch S, Ada L, Canning CG, Al-Zharani M, Dean C. The strength of the ankle dorsiflexors has a significant contribution to walking speed in people who can walk independently after stroke: an observational study. Arch Phys Med Rehabil. 2012 Jun;93(6):1072-6.

6. Liu SH, Hsieh CL, Wei TS, Liu PT, Chang YJ, Li TC. Acupuncture stimulation improves balance function in stroke patients: a single-blinded controlled, randomized study. Am J Chin Med. 2009;37(3):483-94.

7. Hill TR, Gjellesvik TI, Moen PM, Tørhaug T, Fimland MS, Helgerud J, Hoff J. Maximal strength training enhances strength and functional performance in chronic stroke survivors. Am J Phys Med Rehabil. 2012 May;91(5):393-400.

8. Wei TS, Hu CH, Wang SH, Hwang KL. Fall Characteristics, functional mobility and bone mineral density as risk factors of hip fracture in the communitydwelling ambulatory elderly. Osteoporos Int. 2001 Dez;12(12):1050-5.

9. Flansbjer UB, Lexell J, Brogårdh C. Long-term benefits of progressive resistance training in chronic stroke: a 4-year follow-up. J Rehabil Med. 2012 Mar;44(3):218-21.

10. Saunders DH, Sanderson M, Brazzelli M, Greig CA, Mead GE. Physical fitness training for stroke patients. Cochrane Database Syst Rev. 2013 Oct 21;10:3316.

11. Bohannon RW, Andrews AW. Interrater reliability of hand-held dynamometry. Phys Ther. 1987 Jun;67(6):931-933.

12. Shahgholi L, Bengtson KA, Bishop AT, Shin AY, Spinner RJ, Basford JR, et al. A comparison of manual and quantitative elbow strength testing. Am J Phys Med Rehabil. 2012;91:856-62.
13. Kendall FP, McCreary EK, Provance PG, Rodgers MM, Romani WA. Músculos provas e funções. 5 ed. São Paulo: Manole; 2007.

14. Bohannon RW. Manual muscle test scores and dynamometer test scores of knee extension strength. Arch Phys Med Rehabil. 1986 Jun;67(6):390-392.

15. Bohannon RW. Test-retest reliability of hand-held dynamometry during a single session of strength assessment. Phys Ther. 1986 Fev;66(2):206-209.

16. Stark T, Walker B, Phillips J, Fejer R, Beck R. Handheld dynamometry correlation with the gold standard isokinetic dynamometry: a systematic review. PM\&R. 2011;3(5):472-9.

17. Bohannon RW. Measurement, nature, and implications of skeletal muscle strength in patients with neurological disorders. Clin Biomech. 1995 Set;10(6):283-92.

18. Martins JC, Teixeira-Salmela LF, Aguiar LT, Souza LAC, Lara EM, Faria CDCM. Assessment of the strength of the trunk and upper limb muscles in stroke subjects with portable dynamometry: a literature review. Fisioter. mov. 2015 Mar; 28(1):169-86.

19. Sisto $S$, Dyson-Hudson T. Dynamometry testing in spinal cord injury. J Rehabil Res Dev. 2007;44(1):123-36.

20. Wu H, Tang J, Lin X, Lau J, Leung P, Woo J, et al. Acupuncture for stroke rehabilitation (Review). Cochrane Database of Systematic Reviews. 2006;(3):1-20.

21. Bohannon RW. Strength of lower limb related to gait velocity and cadence in stroke patients. Physiother Canada. 1986 Jul-Ago;38(4):204-6.

22. Bohannon RW. Gait performance of hemiparetic stroke patients: selected variables. Arch Phys Med Rehabil. 1987 Nov; 68(11):777-81.

23. Riddle DL, Finucane SD, Rothstein JM, Walker ML. Intrasession and intersession reliability of hand-held dynamometer measurements taken on brain-damaged patients. Phys Ther. 1989 Mar;69(3):182-94.

24. Bohannon RW, Walsh S. Association of paretic lower extremity muscle strength and standing balance with stair-climbing ability in patients with stroke. J Stroke Cerebrovasc Dis. 1991;1(3):129-33.

25. Bohannon RW. Standing balance, lower extremity muscle strength, and walking performance of patients referred for physical therapy. Percept Mot Skills. 1995 Abr;80(2):379-85. 
26. Stein RB, Zehr EP, Lebiedowska MK, Popovic DB, Scheiner A, Chizeck HJ. Estimating mechanical parameters of leg segments in individuals with and without physical disabilities. IEEE Trans Rehabil Eng. 1996 Set;4(3):201-11.

27. Cameron D, Bohannon RW. Criterion validity of lower extremity Motricity Index scores. Clin Rehabil. 1999 Abr;14(2):208-11.

28. Andrews AW, Bohannon R.W. Distribution of muscle strength impairments following stroke. Clin Rehabil. 2000 Fev;14(1):79-87.

29. Bohannon RW. Measuring Knee Extensor Muscle Strength. Am J Phys Med Rehabil. 2001 Jan;80(1):13-8.

30. Andrews AW, Bohannon RW. Short-term recovery of limb muscle strength after acute stroke. Arch Phys Med Rehabil. 2003 Jan;84(1):125-30.

31. Lin PY, Yang YR, Cheng SJ, Wang RY. The relation between ankle impairments and gait velocity and symmetry in people with stroke. Arch Phys Med Rehabil. 2006 Abr;87(4):562-8.

32. Akbari A, Karimi H. The Effect of strengthening exercises on exaggerated muscle tonicity in chronic hemiparesis following stroke. J Med Sci. 2006 Maio-Jun;6(3):382-8.

33. Moriello C, Mayo NE. Development of a positionspecific index of muscle strength to be used in stroke evaluation. Arch Phys Med Rehabil. 2006 Nov;87(11):1490-1495.

34. Guimarães RM, Pereira JS, Batista LA, Fortalecimento do músculo solear: impacto na cinemática da marcha de indivíduos hemiparéticos. Fisioter Mov. 2007 Jul-Set;20(3):11-6.

35. Bale M, Strand LI. Does function strength training of the leg in subacute stroke improve physical performance? A pilot randomized controlled trial. Clin Rehabil. 2008 Out-Nov;22(10-11):911-21.

36. Faria CDCM, Teixeira-Salmela LF, Nadeau S. Effects of the direction of turning on the Time Up \& Go Test with stroke subjects. Top Stroke Rehabil. 2009 Maio-Jun;16(3):196-206.

37. Mong Y, Teo TW, Ng SS. 5-repetition sit-to-stand test in subjects with chronic stroke: reliability and validity. Arch Phys Med Rehabil. 2010 Mar;91(3):407-413.
38. Ng SSM. Contribution of subjective balance confidence on functional mobility in subjects with chronic stroke. Disabil Rehabil. 2011;33(23-24):2291-2298.

39. Kiyama R, Fukudome K, Hiyoshi T, Umemoto A, Yoshimoto Y, Maeda T. The loss of dexterity in the bilateral lower extremities in patients with stroke. J ApplBiomech. 2011 Maio;27(2):122-129.

40. Cooper A, Alghamdi GA, Alghamdi MA, Altowaijri A, Richardson $\mathrm{R}$. The relationship of lower limb muscle strength and knee joint hyperextension during the stance phase of gait in hemiparetic stroke patients. Physiother Res Int. 2011 Set;17(3):150-156.

41. Wong SS, Yam MS, Ng SS. The Figure-of-Eight Walk test: reliability and associations with stroke-specific impairments. Disabil Rehabil. 2013;35(22):1896-902.

42. Michaelsen SM, Ovando AC, Bortolotti A, Bandini B. Strength deficit of knee flexors is dependent on hip position in adults with chronic hemiparesis. Braz J Phys Ther. 2013 Jan-Feb;17(1):86-91.

43. Ng SS, Ng HH, Chan KM, Lai JC, To AK, Yeung CW. Reliability of the 12-step ascend and descend test and its correlation with motor function in people with chronic stroke. J Rehabil Med. 2013 Feb;45(2):123-9.

44. Souza LA, Martins JC, Teixeira-Salmela LF, Lara EM, Moura JB, Aguiar LT, de Morais Faria CD. Validity and reliability of the modified sphygmomanometer test to assess strength of the lower limbs and trunk muscles after stroke. J Rehabil Med. 2014 Jul;46(7):620-8.

45. Prasomsri J, Jalayondeja C, Bovonsunthonchai S, Khemthong S. Walking and stair climbing abilities in individuals after chronic stroke with and without mental health problem. J Med Assoc Thai. 2014 Jul;97Suppl 7:S10-5.

46. Kim CY, Lee JS, Kim HD, Kim JS. The effect of progressive task-oriented training on a supplementary tilt table on lower extremity muscle strength and gait recovery in patients with hemiplegic stroke. Gait Posture. 2015 Feb;41(2):425-30.

47. Ng SS, Chan LH, Chan CS, Lai SH, Wu WW, Tse MM, Fong SS. Parallel walk test: its correlation with balance and motor functions in people with chronic stroke. Arch Phys Med Rehabil. 2015 May;96(5):877-84.

48. Portney LG, Watkins MP. Foundations of Clinical Research: Applications to practice. 2. ed. Upper Saddle River, New Jersey: Prentice Hall; 2000. 
49. Jones RD, Donaldson IM, Parkin PJ. Impairment and recovery of ipsilateral sensory-motor function following unilateral cerebral infarction. Brain. 1989 Fev;112(Pt 1):113-132.

50. Sunnerhagen KS, Svantesson U, Lönn L, Krotkiewski M, Grimby G. Upper motor neuron lesions: their effect on muscle performance and appearance in stroke patients with minor motor impairment. Arch Phys Med Rehabil. 1999 Fev;80(2):155-61.

51. Potempa K, Braum LT, Tinknell T, Popovich J. Benefits of aerobics exercise after stroke. Sports Med. 1996 Maio;21(5):337-346.

52. Hamrin E, Eklund G, Hillgren AK, Borges O, Hall J,Hellström 0. Muscle strength and balance in poststroke patients. Ups J Med Sci. 1982;87(1):11-26.

53. Magee DJ. Avaliação Musculoesquelética. 4. ed. Barueri, São Paulo: Manole; 2005.

54. Faria CDCM, Aguiar LT, Lara EM, Souza LAC, Martins JC, Teixeira-Salmela LF. Dynamometry for the Assessment of Grip, Pinch, and Trunk Strength in Subjects with Chronic Stroke: Reliability and Various Sources of Outcome Values. International J Phys Med \& Rehabil. 2013;1:1-5.

55. Aguiar LT, Albuquerque JA, Lara EM, Martins JC, Teixeira-Salmela LF, Faria CDCM. Dynamometry for the measurement of muscle strength of grip, pinch, and trunk in the subacute phase of stroke: reliability and various sources of outcome values. Braz J Phys Ther Forthcomig; 2015.
56. Martins JC, Teixeira-Salmela LF, Aguiar LT, Lara EM, Souza LAC, Faria CDCM. Avaliação da força muscular de indivíduos com AVE: quantas repetições são necessárias? In: 3 Congresso Brasileiro de Fisioterapia Neurofuncional (COBRAFIN), 2014, Belo Horizonte. Anais do 3o Congresso Brasileiro de Fisioterapia Neurofuncional (COBRAFIN), 2014.

57. Brum PC, Forjaz CLM, Tinucci T, Negrão CE. Adaptações agudas e crônicas do exercício físico no sistema cardiovascular. Rev Paul Educ Fís. 2004 Ago;18:21-31.

58. Fernandes AA, Marins JCB. Teste de força de preensão manual: análise metodológica e dados normativos em atletas. Fisioter Mov. 2011 Jul-Set;24(3):567-78.

59. Nogueira DV, Silva SB, Abreu LC, Valenti VE, Fujimori M, Monteiro CBM et al. Effect of the rest interval duration between contractions on muscle fatigue. Rev Biomed Eng Online. 2012; 11:89.usc

Recebido: 12/04/2013

Received: 04/12/2013

Aprovado: 26/06/2015 Approved: 06/26/2015 